\title{
Change in Primary $(\mathrm{Cr}, \mathrm{Fe})_{7} \mathrm{C}_{3}$ Carbides Induced by Electric Current Pulse Modification of Hypereutectic High Chromium Cast Iron Melt
}

\author{
Baoyu Geng ${ }^{1}$, Rongfeng Zhou ${ }^{1,2, *}, \operatorname{Lu~Li}^{1}{ }^{1,2}$, Haiyang $\mathrm{Lv}^{1,3}$, Yongkun $\mathrm{Li}^{1}{ }^{1}$, Dan Bai ${ }^{1}$ and \\ Yehua Jiang ${ }^{1}$ \\ 1 Faculty of Materials Science and Engineering, Kunming University of Science and Technology, \\ Kunming 650093, China; gengbaoyu@kmust.edu.cn (B.G.); lilukust@126.com (L.L.); \\ lvhaiyang@cqwu.edu.cn (H.L.); liyongkun@kmust.edu.cn (Y.L.); baidankmust@163.com (D.B.); \\ jiangyehua@kmust.edu.cn (Y.J.) \\ 2 Research Center for Analysis and Measurement, Kunming University of Science and Technology, \\ Kunming 650039, China \\ 3 School of Materials and Chemical Engineering, Chongqing University of Arts and Sciences, \\ Chongqing 402160, China \\ * Correspondence: zhourongfeng@kmust.edu.cn; Tel.: +86-137-0886-8341; Fax: +86-871-6511-5524
}

Received: 17 November 2018; Accepted: 14 December 2018; Published: 22 December 2018

\begin{abstract}
In this work, an electric current pulse (ECP) of 500A was applied on a hypereutectic high chromium cast iron (HHCCI) melt before it began to solidify, and the effect of ECP on primary carbides was investigated. The characteristics of the primary carbides were analyzed by X-ray diffraction (XRD), electron probe micro-analyzer (EPMA), transmission electron microscopy (TEM), micro hardness tester, and other techniques. The results showed that ECP not only refined the primary $(\mathrm{Cr}, \mathrm{Fe})_{7} \mathrm{C}_{3}$ carbides, but also decreased the average content of $\mathrm{Cr}$ in the primary carbides. At the same time, the average value of micro hardness of the primary carbides increased by about $84 \mathrm{Kgf} / \mathrm{mm}^{2}$, which contradicts existing knowledge that hardness increases with an increase in $\mathrm{Cr}$ content. XRD analysis showed that the crystal structure of the primary carbides did not change. The results of EPMA indicated that the $\mathrm{Cr} / \mathrm{Fe}$ ratio gradually decreased from the center to the edges of the carbide particles. Further investigation revealed that the uneven distribution of elements caused by ECP led to an increase in defects (including twins, antiphase boundaries, and dislocations). This increase in defect density is the main reason for the increase in micro hardness instead of the expected decrease. The mechanism of the change in primary carbides was analyzed in detail in this paper, which has provided a new method for the refinement of primary carbides and for improving the properties of primary carbides.
\end{abstract}

Keywords: $(\mathrm{Cr}, \mathrm{Fe})_{7} \mathrm{C}_{3}$; electric current pulse; micro defect; micro hardness

\section{Introduction}

M7C3 carbides are the main strengthening phase in hypereutectic high chromium cast iron (HHCCI) due to their greater strength and hardness (where $\mathrm{M}$ is mainly $\mathrm{Fe}$ and $\mathrm{Cr}$, and $\mathrm{C}$ is carbon) $[1,2]$. The morphology, distribution, composition, and internal micro-defects of the primary carbides have important effects on the properties of the alloy [1,3,4]. Investigation of carbide characteristics and corresponding influencing factors is beneficial to improving the properties of alloys.

M7C3 carbides have been widely studied over the past century, which has provided a good foundation of knowledge for their further development. Regarding the morphology of carbides, it has been reported that primary carbides grow as rods while eutectic carbides grow as blades in longitudinal 
sections and as fine rods in transverse sections [5-7]. With regard to the structure of carbide crystals, three crystal structures have been proposed; these are the trigonal symmetry structure proposed by Westgren (1935) [8], the hexagonal crystal system proposed by Herbstein and Snyman (1964) [9], and the orthorhombic crystal system proposed by Rouault (1970) [10]. It has been pointed out that there are defects such as twins, antiphase boundaries, and dislocations in M7C3 carbides [11-15]. Regarding the performance of carbides, it has been found that the hardness of carbides increases with an increase in $\mathrm{Cr}$ content and that toughness follows the opposite trend $[6,16]$. It has been proven by theoretical calculation that an increase in $\mathrm{Cr}$ content is helpful to improving the hardness of carbides $\left((\mathrm{Cr}, \mathrm{Fe})_{7} \mathrm{C}_{3}\right)[17,18]$. Studies have shown that the hardness and toughness of carbides in different sections (longitudinal sections and transverse sections) are anisotropic [6]. Previous reports [19] have suggested that the addition of alloy elements such as Mo and Ni can change the properties of carbides, but this undoubtedly increases the cost. Although much research has been performed on the characteristics of M7C3 carbides, the methods and mechanisms for improving carbide properties are still a focus in the field of ferrous metal materials.

Electric current pulse (ECP) modification is a suitable method for improving the microstructure and properties of materials because it is highly efficient, clean, and inexpensive. ECP processing has been studied and applied widely in many fields since it was first developed. Some of its applications include improving the plastic and fatigue properties of materials, the phase transition of solid metals, and controlling the solidification process of alloys [20-26]. Especially in the last 30 years, the application of ECP in solidification control processes has become a research focus. However, scholars have different explanations for the mechanism of grain refinement caused by ECP. These theories can be divided into two classes according to the temperature interval in which ECP is applied. The first theory focuses on the application of ECP to the solidification interval, and it mainly involves crystallization rain theory and dendrite breaking theory $[22,23,27]$. The second type focuses on the application of ECP to the melt interval and is based on the inoculation theory proposed by Wang et al. [28-30]. They have pointed out that ECP can distort the external electron layer of the crystal embryo (cluster) in pure metal melts, and that this distortion facilitates the refinement of grains [30]. Our previous studies have shown that ECP can effectively refine primary and eutectic carbides [31]. Based on our previous research, the present work aims to study the effects of ECP on the morphology, components, micro defects, and micro hardness of primary carbides in HHCCI. The mechanism of induction caused by ECP is also investigated.

\section{Materials and Methods}

In this work, the experimental material, $\mathrm{HHCCI}$, contained $19.40 \% \mathrm{Cr}, 3.84 \% \mathrm{C}, 2.70 \% \mathrm{Si}$ and balance Fe by weight. The start and end temperatures of melting were $1276{ }^{\circ} \mathrm{C}$ and $1337^{\circ} \mathrm{C}$, respectively, which were obtained using a simultaneous thermal analyzer (NETZSCH STA 449F3, NETZSCH, Selb, Germany). The experimental preformed samples $(\Phi 18 \mathrm{~mm} \times 150 \mathrm{~mm})$ were first prepared by machining. The preformed samples were then sealed in an alundum tube by sodium silicate bonded sand and two nickel electrodes. The experimental device is shown in Figure 1. The preformed samples were heated for $160 \mathrm{~min}$ to raise the temperature to $1355{ }^{\circ} \mathrm{C}$ in a muffle furnace (YFK60_600/160, Shanghai Yifeng Electric Furnace Company, Shanghai, China), and then soaked at $1355^{\circ} \mathrm{C}$ for $3 \mathrm{~min}$. ECP of $500 \mathrm{~A}$ (500 A is the peak value of ECP) was passed through the melt between $1355{ }^{\circ} \mathrm{C}$ and $1337^{\circ} \mathrm{C}$ by a sharp ECP generator. Subsequently, the melt solidified and was allowed to cool down to room temperature in the muffle furnace. According to our previous study, the optimal ECP parameters for grain refinement were $500 \mathrm{~A}, 45 \mathrm{~Hz}$, and $10 \mu$ s [32]. Therefore, this set of parameters was used in this experiment. The temperature history of the melt was monitored by thermocouples. In the following sections, the sample treated by ECP is referred to as the ECP sample. The same heating, soaking, and cooling methods were used to obtain a comparative sample without pulsed current. This sample is referred to as the non-ECP sample in the following sections. 


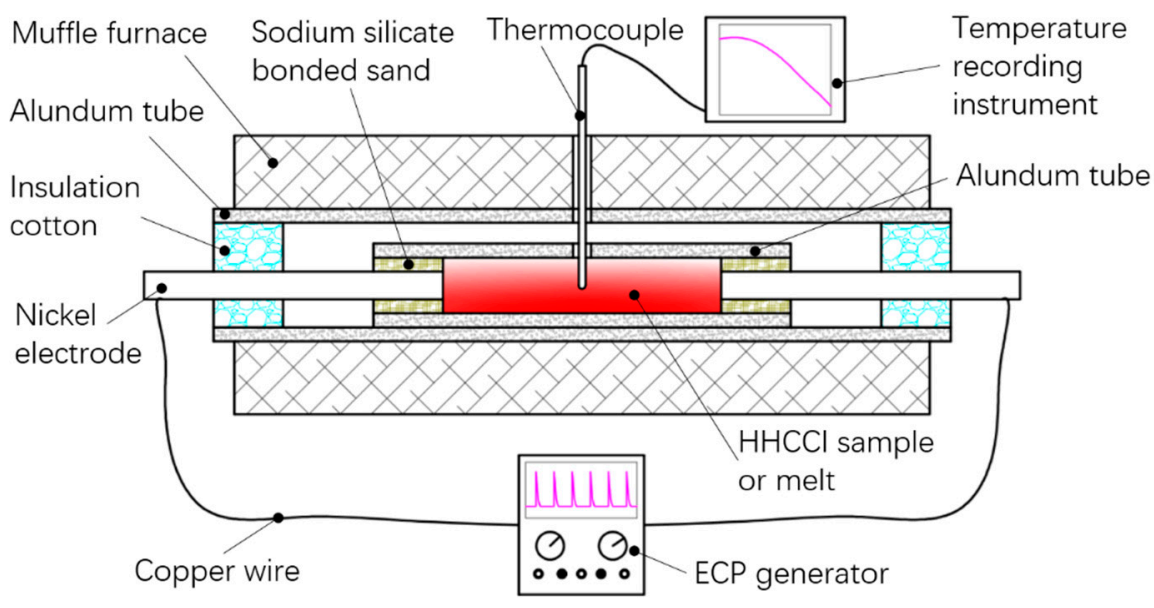

Figure 1. Schematic of the experimental device, where HHCCI is hypereutectic high chromium cast iron and ECP is electric current pulse.

For optical microscope analyses, the samples were etched with $5 \% \mathrm{FeCl}_{3}$ aqueous solution $(5 \mathrm{~g}$ $\mathrm{FeCl}_{3}$ and $95 \mathrm{~mL} \mathrm{H}_{2} \mathrm{O}$ ). The morphology of samples was observed with a Leica optical microscope (Leica, Buffalo Grove, IL, USA). The micro hardness of the transverse sections of the primary carbides was measured with a HVS-1000A hardness tester (LaizhouWeiyi Experiment Machine Company, Lanzhou, China) (with a load of $300 \mathrm{gf}$ and indentation time of $10 \mathrm{~s}$, according to the ASTM E384 standard). The samples were extracted using $45 \% \mathrm{HCl}$ aqueous solution $\left(45 \% \mathrm{HCl}\right.$ and $\left.55 \% \mathrm{H}_{2} \mathrm{O}\right)$ over $120 \mathrm{~h}$, and only primary carbides were selected manually. In order to speed up the extraction process, samples were wire-cut into $2 \mathrm{~mm}$ sheets and placed in $45 \% \mathrm{HCl}$ aqueous solution. Then, ultrasonic waves were used to oscillate the $\mathrm{HCl}$ aqueous solution and the samples for $10 \mathrm{~min}$ every $24 \mathrm{~h}$ during extraction. Carbide particles were manually ground into powders for $0.5 \mathrm{~min}$ in an agate grinding dish at room temperature. The particle size after grinding was about $30-60 \mu \mathrm{m}$. X-ray diffraction (XRD) analysis of the powders was carried out with a D/max-3B diffractometer (Rigaku, Tokyo, Japan). XRD with $\mathrm{Cu} \mathrm{K} \alpha$ radiation was used to identify the crystal phase and calculate the lattice parameters at a scanning speed of $0.013^{\circ} / \mathrm{s}$ and a $2 \theta$ range of $35^{\circ}$ to $85^{\circ}$. In order to calculate the lattice parameters accurately, a standard silicon was used to calibrate $2 \theta$ of the XRD data. Morphology analysis of carbide powders was carried out by scanning electron microscopy (SEM) with a Nova Nano SEM 450 (FEI, Hillsboro, OR, USA). The content and distribution of elements on the transverse sections of the primary carbides were analyzed by electron probe micro-analyzer (EPMA) with a JXA8230 (JEOL, Tokyo, Japan). The area of the electron beam was approximately $1 \mu \mathrm{m}^{2}$. The relative measurement error of the main elements $(\mathrm{Fe}, \mathrm{Cr}$ ) was less than or equal to $2 \%$, and that of $\mathrm{C}$ was less than or equal to $6 \%$. Micro defects in the primary carbides were observed by transmission electron microscopy (TEM) with a Tecnai G2 F30 (operated at an acceleration voltage of $300 \mathrm{KV}$ ) (FEI, Hillsboro, OR, USA). The TEM samples were prepared by focused ion beam (FIB) slicing technique with a TESCAN LYRA3 (TESCAN, Brno, Czech Republic).

\section{Results}

\subsection{Morphology and Micro Hardness of the Primary Carbides}

Figure 2 shows the morphology of the primary carbides in the non-ECP sample and the ECP sample. It was observed that the primary carbides were all hexagonal rods. Compared to the non-ECP sample, the primary carbides of complete hexagonal sections were significantly greater in the ECP sample. The size of the transverse sections of the primary carbides was reduced from about $200 \mu \mathrm{m}$ to $100 \mu \mathrm{m}$. Moreover, the size of the longitudinal sections of the primary carbides was reduced from about $800 \mu \mathrm{m}$ to $200 \mu \mathrm{m}$. Thus, the primary carbides were significantly refined by ECP. It should be mentioned that there was no obvious orientation phenomenon in the solidification structure. Therefore, 
it was difficult to accurately measure the size of the longitudinal directions of the primary carbides. In this experiment, grain size could only be evaluated by measuring the approximate size of transverse and longitudinal sections within the same section.
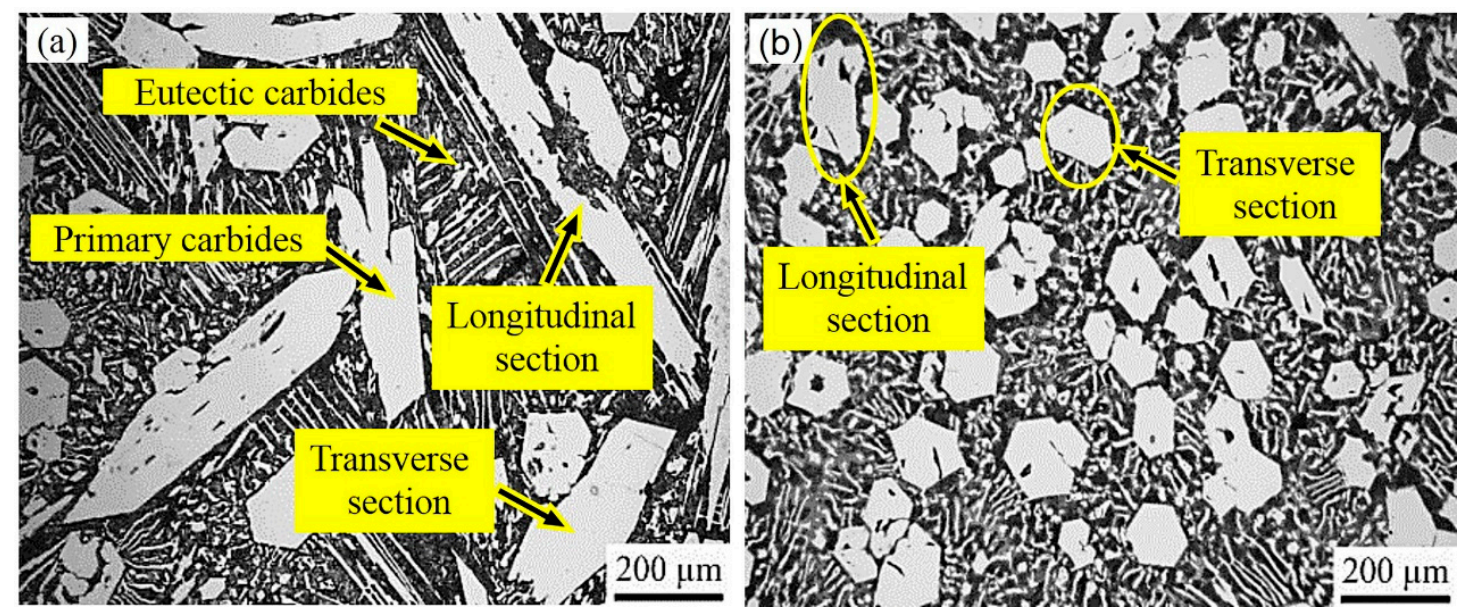

Figure 2. Morphology of the primary carbides (samples were etched with $5 \% \mathrm{FeCl}_{3}$ aqueous solution): (a) non-ECP sample; (b) ECP sample.

The micro hardness of five primary carbide particles in each sample were measured from transverse sections and the average values were obtained. Figure 3 shows indentation marks on transverse sections of the primary carbides. The average micro hardness value was $1409 \pm 44 \mathrm{Kgf} / \mathrm{mm}^{2}$ for the non-ECP sample. It was $1493 \pm 32 \mathrm{Kgf} / \mathrm{mm}^{2}$ for the ECP sample. These results indicate that the micro hardness of the primary carbides was improved slightly after ECP modification of the HHCCI melt.
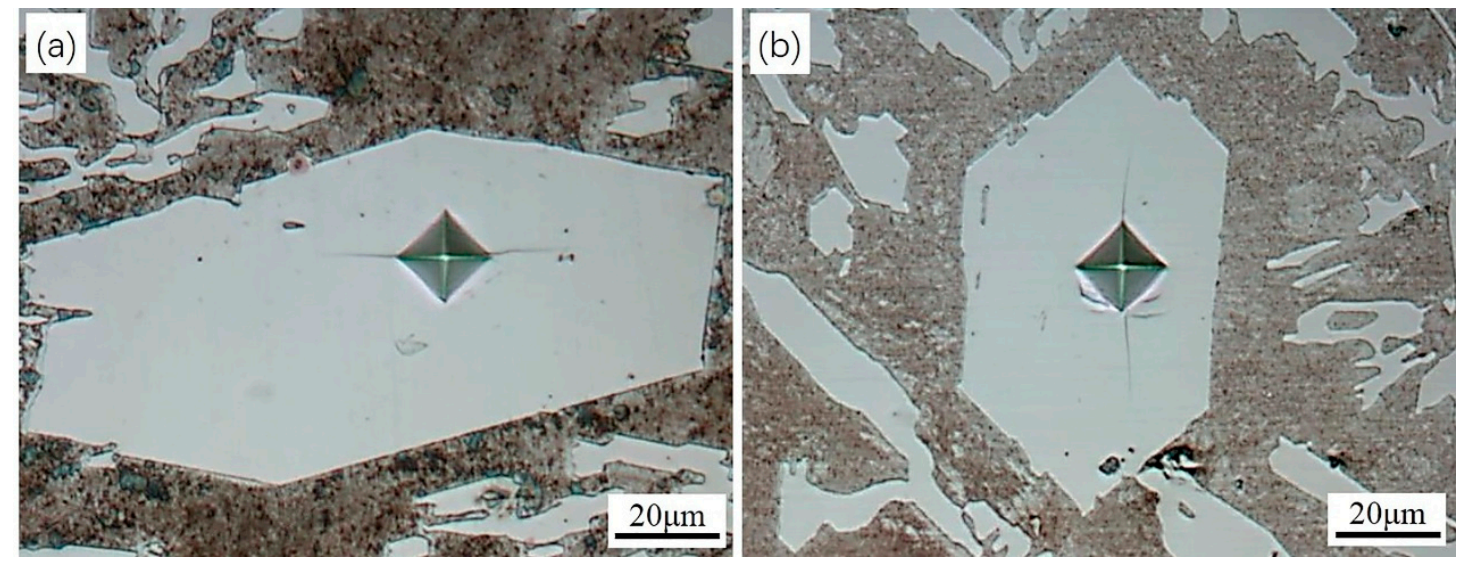

Figure 3. Indented transverse primary carbides: (a) non-ECP sample; (b) ECP sample. The load was $300 \mathrm{gf}$ and the time of holding stage was $10 \mathrm{~s}$ at the load peak.

\subsection{Crystal Structure and Lattice Parameters of Primary Carbides}

XRD analysis showed that the crystal structures of the primary carbides in both samples were not different and that they were M7C3 carbides (Figure 4). They had the orthorhombic crystal structure proposed by Rouault. However, compared to the non-ECP sample $(\mathrm{a}=6.965 \AA, \mathrm{b}=12.030 \AA$ and $\mathrm{c}=4.500 \AA)$, the lattice parameters of primary carbides in the ECP sample $(\mathrm{a}=6.960 \AA, \mathrm{b}=12.018 \AA$ and $c=4.495 \AA$ ) were smaller by $0.005,0.012$, and 0.005 , respectively.

In addition, the diffraction peak intensities of some crystal planes in the ECP sample were larger than those in the non-ECP sample, including for the (150), (060), (260), (080), (550), and (390) planes. 

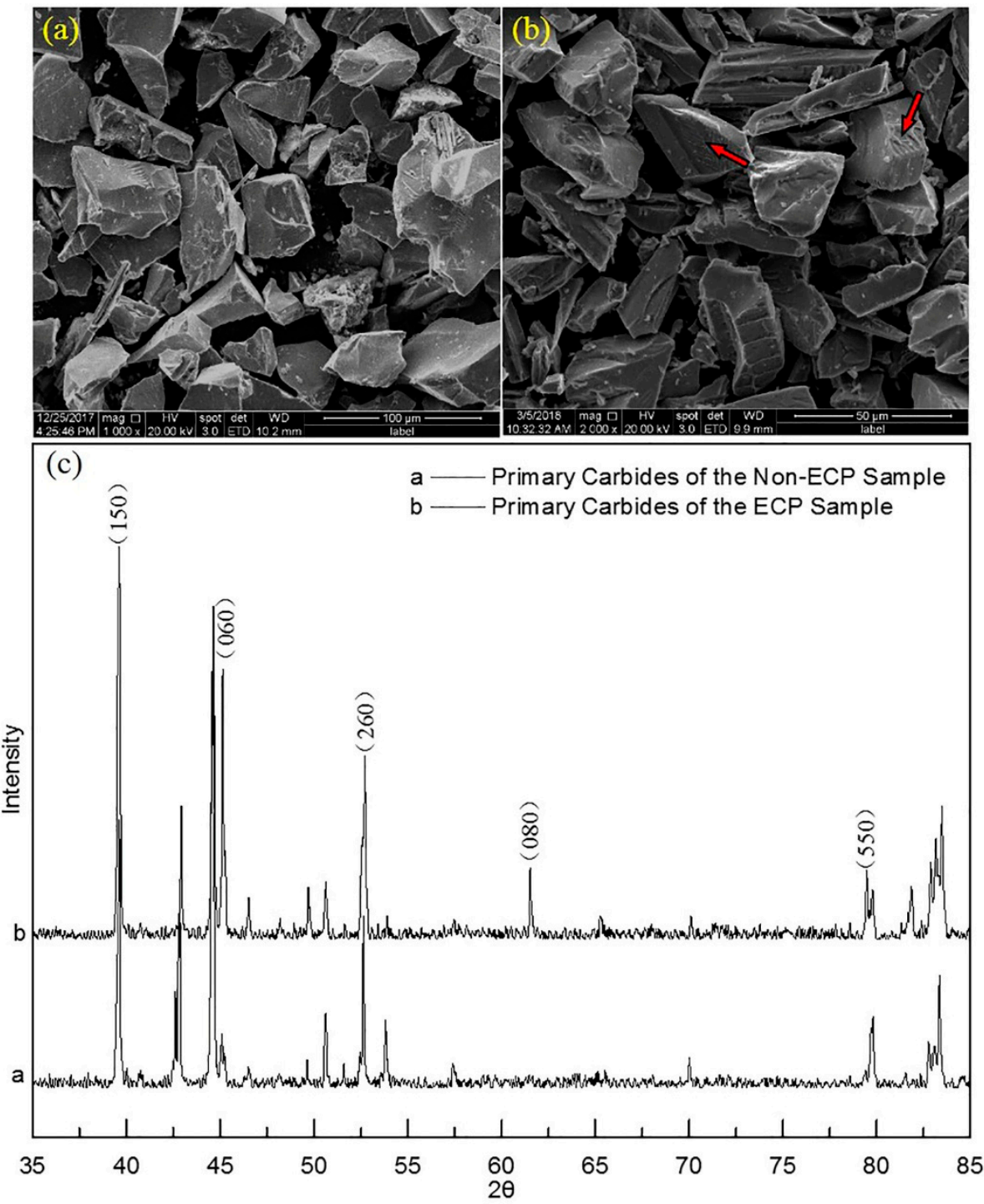

Figure 4. (a) Scanning electron microscopy (SEM) image of primary carbide powders for the non-ECP sample; (b) SEM image of primary carbide powders for the ECP sample; (c) corresponding X-ray diffraction $(\mathrm{XRD})$ pattern.

\subsection{Content and Distribution of Elements in Primary Carbides}

The contents of elements in the transverse sections of primary carbides were analyzed by EPMA. Compared with the non-ECP sample, the average $\mathrm{Cr}$ content of primary carbides in the ECP sample was lower and the average Fe content was higher (Table 1). Considering the relatively large measurement error of $C$ content, it can be assumed that both samples had equal $C$ content. The calculated results showed that the $(\mathrm{Fe}, \mathrm{Cr}) / \mathrm{C}$ ratio of primary carbides was $7 / 3.3$ for the non-ECP sample, and $7 / 3.2$ for the ECP sample. The ratios of elements in the primary carbides of the two samples agreed with those of the M7C3 carbides. This was consistent with the XRD results.

Table 1. Average contents of elements in primary carbides in the HHCCI.

\begin{tabular}{cccc}
\hline & $\mathbf{F e} /(\mathbf{a t} \%)$ & $\mathbf{C} / \mathbf{( a t} \%)$ & $\mathbf{C r} / \mathbf{( a t} \mathbf{)})$ \\
\hline Non-ECP Sample & $28.82 \pm 0.35$ & $32.07 \pm 0.12$ & $39.11 \pm 0.23$ \\
ECP Sample & $29.97 \pm 0.25$ & $31.89 \pm 0.07$ & $38.14 \pm 0.17$ \\
\hline
\end{tabular}


Figure 5a,d shows the EPMA positions of the two samples using SEM imaging with backscattering electrons. Figure $5 \mathrm{~b}-\mathrm{e}$ shows the changes in elemental contents in the two samples, respectively. Figure $5 \mathrm{c}, \mathrm{f}$ shows the trend of the atomic ratios of $\mathrm{Cr} / \mathrm{Fe}$. It can be seen that the $\mathrm{Cr} / \mathrm{Fe}$ atomic ratios were almost constant in the central region of the primary carbides and then decreased suddenly at the edges for the non-ECP sample (Figure $5 \mathrm{c}$ ). However, the ratios gradually decreased from the center to the edges for the ECP sample (Figure 5f). In other words, $\mathrm{Cr}$ content gradually decreased and Fe content gradually increased from the center to the edges.
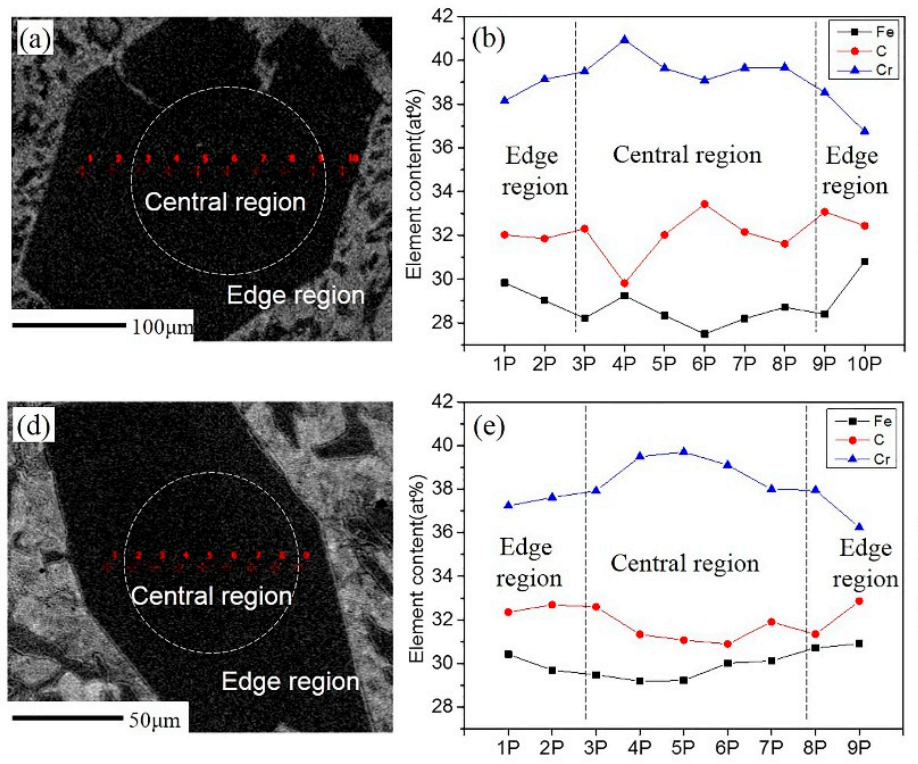
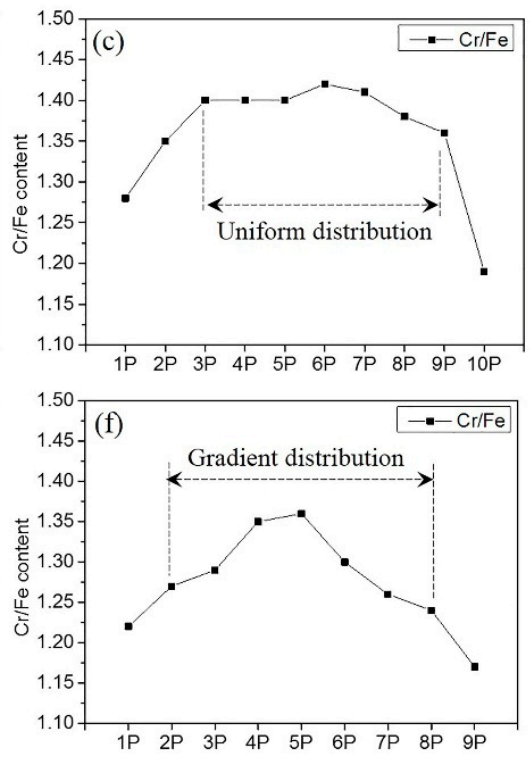

Figure 5. Contents and distribution of elements in the transverse sections of primary carbides. For the non-ECP sample: (a) electron probe micro-analyzer (EPMA) positions, (b) the distribution of elements, and (c) the trend of $\mathrm{Cr} / \mathrm{Fe}$ atomic ratios. For the ECP sample: (d) EPMA positions, (e) the distribution of elements, and (f) the trend of $\mathrm{Cr} / \mathrm{Fe}$ atomic ratios.

\subsection{Density of Micro Defects in Primary Carbides}

The selected area diffraction patterns (SADP) from [001] zone axis of the primary carbides in both samples were similar (Figure $6 \mathrm{~b}, \mathrm{e}$ ). According to analysis of the SADP, it could be concluded that they were M7C3 carbides. However, it can be clearly seen from the bright-field TEM micrographs that there were more dark stripes with regular arrangements in the carbides of the ECP sample than the non-ECP sample (the yellow arrow in Figure $6 \mathrm{a}, \mathrm{d}$ ). The angle of these dark stripes was $60^{\circ}$ or $120^{\circ}$. The dark stripes were twins and antiphase boundaries [11]. It is important to note that the densities of the twins and antiphase boundaries in this work were lower compared to other literature data [11-15]. 

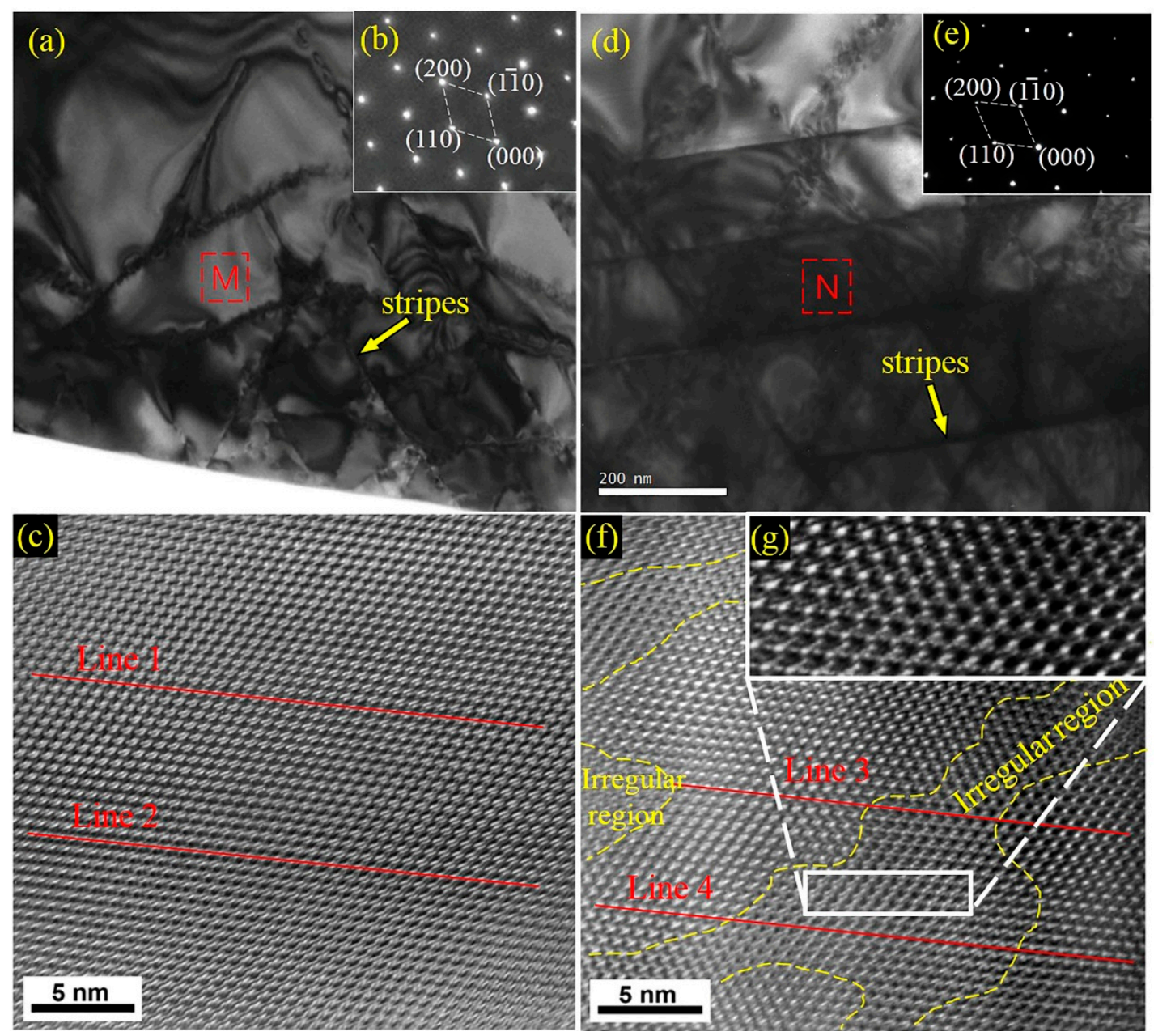

Figure 6. (a) Bright-field transmission electron microscopy (TEM) micrograph of primary carbides in the non-ECP sample, where area $M$ is the position for high resolution TEM (HRTEM); (b) corresponding selected area diffraction patterns (SADP); and (c) corresponding HRTEM. (d) Bright-field TEM micrograph of primary carbides in the ECP sample, where area $\mathrm{N}$ is the position for HRTEM; (e) corresponding SADP; (f) corresponding HRTEM; and (g) corresponding magnified region.

High resolution TEM (HRTEM) images of the carbides in the two samples obtained from the [001] zone axis are shown in Figure 6c,f. It can be seen that the bright spots in the HRTEM image along the red lines 1 and 2 have a regular arrangement from left to right in Figure 6c. However, there is a deviation in the arrangement of the bright spots along red lines 3 and 4 from left to right in Figure $6 f$. The left ends of red lines 3 and 4 were on bright spots, while the right ends were in the gap between the bright spots. Although no information concerning the detailed atomic arrangements can be obtained from the HRTEM image, HRTEM provides a powerful means for the direct observation of irregularities. Thus, it was observed that the lattice arrangements were regular at the left and right ends of the red lines 3 and 4, but the middle region (i.e., the region between the yellow dashed curves) was irregular. This irregular region was similar to a mixed dislocation with a width of $2-10 \mathrm{~nm}$ (Figure $6 \mathrm{~g}$ ). Other researchers have found dislocations in primary carbides [33]. By analyzing the bright-field TEM micrographs and HRTEM images, it can be seen that not only substructures (the twins or antiphase boundaries) but also dislocations within the substructures increased in the primary carbides of the ECP sample. 


\section{Discussion}

\subsection{Refinement of Primary Carbides Induced by ECP Melt Modification}

ECP can distort the external electron layer of the crystal embryo (cluster) in the melt (Figure 7). This distortion facilitates the combination of free atoms in the melt with the crystal embryo. In addition, according to electromigration efficiency, metal ions will gain additional energy under the action of an electric field. The additional energy can reduce the activation energy for diffusion across a solid-liquid interface. These two factors can lead to an increase in the size of the crystal embryo. Larger crystal embryos are conducive to the subsequent formation of primary carbide nuclei and to the refinement of primary carbide grains.

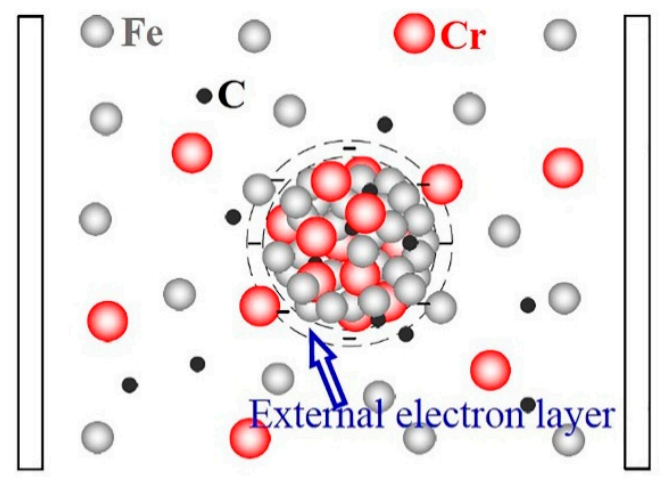

(a)

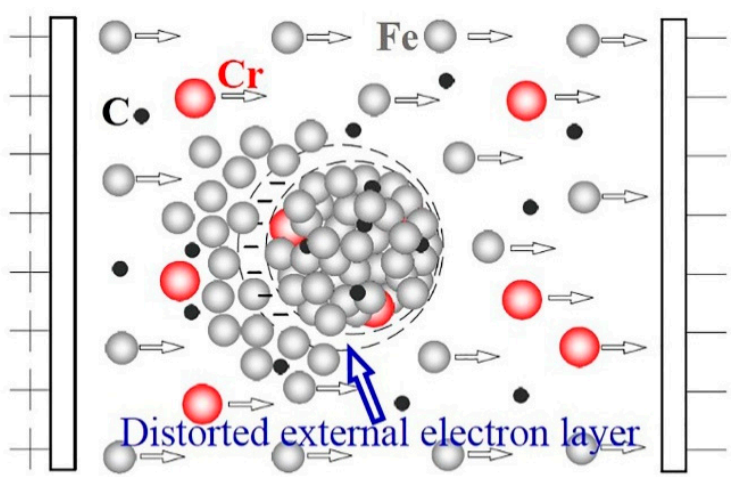

(b)

Figure 7. Schematic of the crystal embryo growth of primary carbides in the two samples: (a) non-ECP sample; (b) ECP sample.

It is well known that the solidification process of alloys is different from that of pure metals. Different types of ions will obtain different energies under the action of the same electric field. According to the free electron theory of metals, the number of valence electrons of $\mathrm{Cr}$ is $6\left(3 \mathrm{~d}^{5}\right.$ $\left.4 s^{1}\right)$, and that of Fe is $8\left(3 d^{6} 4 s^{2}\right)$. The electric quantity of a Fe ion core is greater than that of a Crion core when the current passes through the melt. However, their relative atomic masses are about the same $\left(\mathrm{A}_{\mathrm{Cr}}=52.00 \mathrm{~g} / \mathrm{mol}, \mathrm{A}_{\mathrm{Fe}}=55.85 \mathrm{~g} / \mathrm{mol}\right)$. Due to the difference in their specific charges (specific charge being $\mathrm{q} / \mathrm{m}$, where $\mathrm{q}$ is charge and $\mathrm{m}$ is mass), the energy obtained by a Fe ion core is greater than that obtained by a $\mathrm{Cr}$ ion core during the same period of time under the same electric field. Fe ion cores with high energy combine more easily with crystal embryos in the nucleation stage (Figure $7 \mathrm{~b}$ ), which results in decreased content of $\mathrm{Cr}$ in crystal embryos. As the content of $\mathrm{Cr}$ in each crystal embryo decreases, the crystal nucleus of primary carbides increases when the $\mathrm{Cr}$ content of the alloy is constant. This is another reason for the increase in crystal nuclei of primary carbides caused by ECP.

Figure 7a shows the growth of crystal embryos without an electric field. The crystal embryo tends to receive $\mathrm{Cr}$ ion cores at the solid-liquid interface because of the higher cohesive energies of $\mathrm{Cr}-\mathrm{C}$. Figure $7 \mathrm{~b}$ indicates growth under an electric field. In this case, the crystal embryo tends to receive more Fe ion cores because the Fe ion cores have higher energy to overcome the binding barrier.

The experiment in this study did not have the physical conditions required for crystallization rain theory and dendrite breaking theory because ECP was stopped at the melting point in this experiment. In addition, according to the slope of the fitting line in Figure 8, it can be seen that the cooling rate of the ECP sample was $0.12{ }^{\circ} \mathrm{C} / \mathrm{s}$ and that of the non-ECP sample was $0.11^{\circ} \mathrm{C} / \mathrm{s}$. The cooling rates of the two samples were quite similar and this slight difference can be neglected. Therefore, electromagnetic stirring did not cause accelerated loss of melt heat and it did not contribute significantly to the increase in nucleus quantity, possibly because the cooling mode was in-furnace cooling. It is worth noting that there were no characteristic stops in the cooling curve. The temperature range of the primary carbides precipitation reaction was large and the cooling rate was very small in this experiment (the cooling 
rate of melt is $1 \sim 100{ }^{\circ} \mathrm{C} / \mathrm{s}$ for mold casting; however, it was $0.11^{\circ} \mathrm{C} / \mathrm{s}$ or $0.12{ }^{\circ} \mathrm{C} / \mathrm{s}$ in this experiment), which were conducive to the release of latent heat of crystallization. This may be the reason for why there were no characteristic stops in the cooling curve. Solidification reaction only caused a slight decrease in the cooling rate (Figure 8).

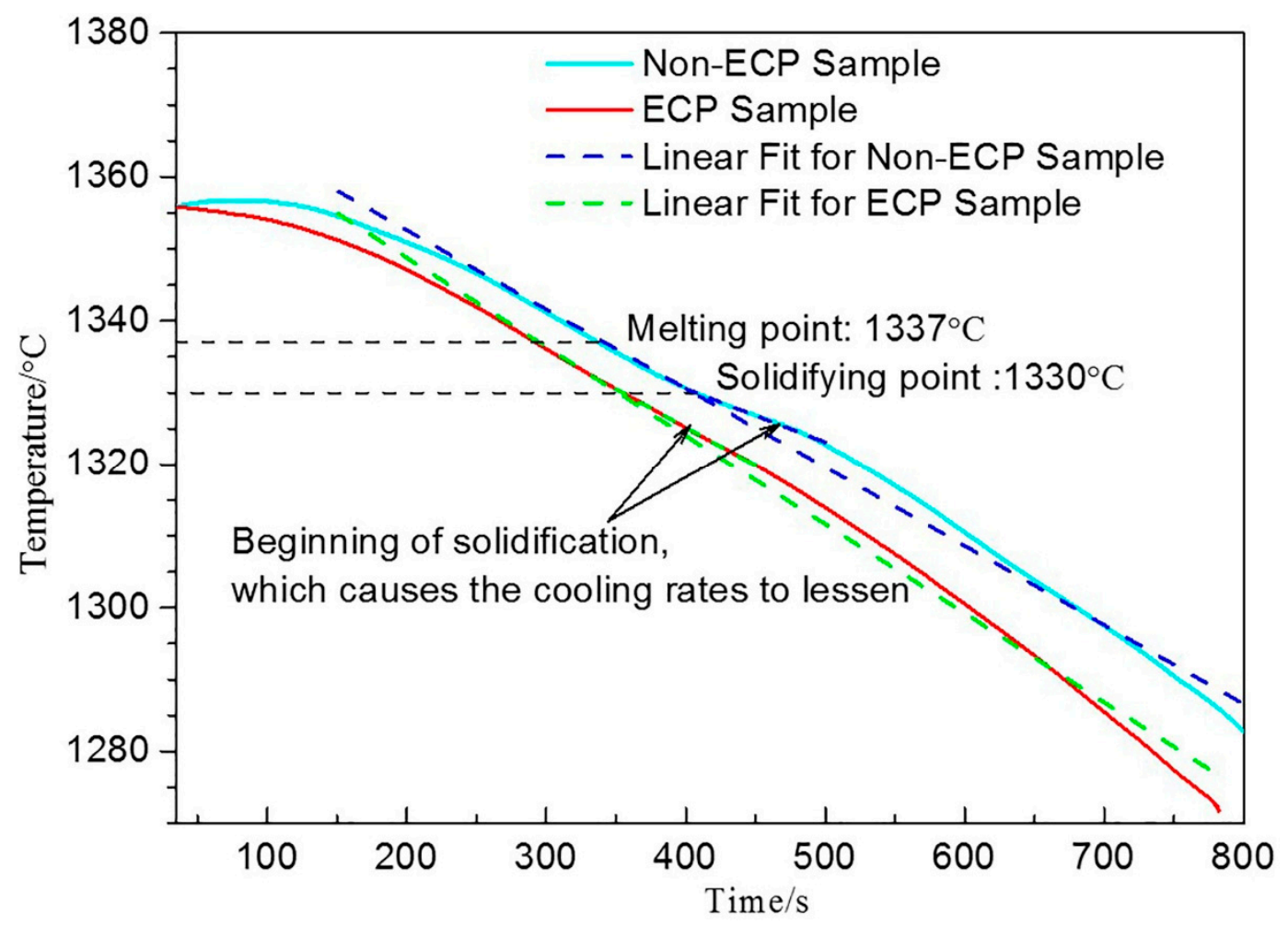

Figure 8. Cooling curve of the HHCCI during solidification.

Overall, the distortion of the external electron layer of crystal embryos and the differences in energy between Fe ions and $\mathrm{Cr}$ ions caused by ECP both contributed to the increase in the number of crystal nuclei during the initial stage of solidification. The increase in the number of primary carbide nuclei led to the refinement of the primary carbides.

\subsection{Effect of ECP on Content and Distribution of Cr in Primary Carbides}

Cr content in primary carbide nuclei is much higher than that in the liquid phase. Carbide nuclei with higher $\mathrm{Cr}$ content tend to receive more $\mathrm{Cr}$ atoms at the solid-liquid interface. Long-range diffusion of $\mathrm{Cr}$ is needed when the nucleus continues to grow. Therefore, $\mathrm{Cr}$ content in carbides is affected by long-range diffusion of $\mathrm{Cr}$.

The ECP sample had more crystal nuclei than the non-ECP sample during solidification. Hence, $\mathrm{Cr}$ in the liquid phase was less than in the non-ECP samples during the initial stage of solidification. A lower concentration of $\mathrm{Cr}$ caused an insufficient diffusion driving force of $\mathrm{Cr}$. This in turn was responsible for the lowering of $\mathrm{Cr}$ content at the solid-liquid interface. As the carbides grew, more and more Fe was received at the solid-liquid interface. This ultimately caused the $\mathrm{Cr}$ content to decrease uniformly from the center to the edges of the carbides (Figure 5e,f). However, the concentration of $\mathrm{Cr}$ in the liquid phase of the non-ECP samples was higher. The larger driving force of diffusion provided a continuous supply of $\mathrm{Cr}$ for the equilibrium growth of carbides until near-eutectic temperature. In the later stages of growth of the primary carbides, $\mathrm{Cr}$ could only diffuse over a short range due to the lower concentration of $\mathrm{Cr}$. More Fe atoms were received at the end of the growth. This resulted in a uniform distribution of $\mathrm{Cr}$ in the central region of the primary carbides and a decrease in $\mathrm{Cr}$ content at the edges (Figure $5 b, c$ ). The schematic of this process is shown in Figure 9. 




Figure 9. Schematic of the growth of carbides: (a) for the non-ECP sample; (b) for the ECP sample.

It is evident that average $\mathrm{Cr}$ content in the carbides of the ECP sample was lower, which was due to the influenced during two stages. First, ECP resulted in lower $\mathrm{Cr}$ content in the crystal embryo during the nucleation stage. Second, although ECP was removed during the growth stage, $\mathrm{Cr}$ content in the carbides was not restored to higher levels because the driving force of long-range diffusion of $\mathrm{Cr}$ was insufficient.

\subsection{Decrease in Lattice Parameters of Primary Carbides}

Compared with the non-ECP sample carbides, the average content of Fe was higher, Cr content was lower, and C content was almost equal in the ECP sample carbides (Table 1). The radius of a Fe atom is smaller than that of a $\mathrm{Cr}$ atom. Therefore, an increase in Fe will inevitably lead to a decrease in the lattice parameters of carbides, which is consistent with the XRD results.

It should be noted that the degrees of grinding for the two kinds of carbides were different because the original size of the carbides in the two samples was different. There were also rod-shaped carbides in the ECP sample and the side face of carbide rods can be seen (the red arrow in Figure $4 \mathrm{~b}$ ). However, the side faces of carbide rods were rarely seen in the non-ECP sample. This orientation exerted some influence on the XRD pattern. The direction along the carbide rods was the (001) direction of crystal [11]. The side face was parallel to $<001>$ orientations (i.e., the index $l$ of the crystal planes was zero). The diffraction opportunities of the side face would thus increase when the rod-shaped carbides existed in powdered form, for the ECP sample. Therefore, the intensity of the diffraction peaks of these crystal planes would increase. In other words, the relative variation of the peak intensities was due to the preferential distribution of the carbides.

\subsection{Increase in Density of Defects and Micro Hardness of Primary Carbides}

Error stacking or omission of $\mathrm{C}$ atoms are considered to be the causes of twins and antiphase boundaries [11-14]. There are two possible factors that can cause error stacking or omission of $\mathrm{C}$ atoms. The first factor is the uneven distribution of $\mathrm{Fe}$ and $\mathrm{Cr}$ elements. A gradient distribution of $\mathrm{Cr}$ and $\mathrm{Fe}$ leads to lattice distortion, which can give the $\mathrm{C}$ atom more chances to stand in the wrong position or to be omitted. The second possible factor is a higher cooling rate (we are not sure about this factor because we have not done the relevant verification in this work but have inferred this from relevant 
literature [11-14]). In another study, it has been found that twins and antiphase boundaries increase with an increase in cooling rates [11]. Preparation processes in that work were normal casting, ion plating, and sputtering. The cooling method for the two samples in our work was furnace cooling, and the cooling rate was lower than with normal casting conditions. The density of twins and antiphase boundaries observed in this work were lower than those reported in previous studies. The increase in twins and antiphase boundaries in the primary carbides of the ECP sample was mainly due to the uneven distribution of $\mathrm{Cr}$ and Fe elements in this experiment, because the cooling rate of the two samples was almost the same.

The $\mathrm{Cr} / \mathrm{Fe}$ ratio gradually decreased from the center to the edges of the carbides, which led to an increase in dislocations in the substructures. An uneven $\mathrm{Cr} / \mathrm{Fe}$ ratio caused differences in the internal and external lattice parameters. In other words, the lattice parameters became smaller from the center to the edges of the carbides. The lattice distortion stress would have been caused by the difference in lattice parameters inside and outside the carbides. In order to reduce this distortion energy, mixed dislocations were generated on (001). Several previous studies have indicated that the micro hardness of $(\mathrm{Fe}, \mathrm{Cr})_{7} \mathrm{C}_{3}$ increases with an increase in $\mathrm{Cr}$ content $[6,16]$. However, the micro hardness of the carbides in the ECP sample (with lower $\mathrm{Cr}$ content) was higher than that of the carbides in the non-ECP sample (with higher $\mathrm{Cr}$ content) in this work. It is well known that dislocation (or twins) strengthening is one of the main ways of strengthening. The hardness was higher mainly because there was a large number of boundaries and entanglement of mixed dislocation in the carbides.

\section{Conclusions}

(1) Compared to the primary carbides in the non-ECP sample, the grain sizes of the carbides in the ECP sample along the transverse and longitudinal directions reduced from about $200 \mu \mathrm{m}$ to $100 \mu \mathrm{m}$, and from about $800 \mu \mathrm{m}$ to $200 \mu \mathrm{m}$, respectively. The average micro hardness of the primary carbides increased from HV $1409 \pm 44 \mathrm{Kgf} / \mathrm{mm}^{2}$ to HV $1493 \pm 32 \mathrm{Kgf} / \mathrm{mm}^{2}$.

(2) ECP did not induce changes in the crystal type of the primary carbides. The crystal structures were both orthogonal. However, the crystal lattice parameters $a, b$, and c decreased by $0.005 \AA$, $0.012 \AA$ and $0.005 \AA$, respectively, because the average content of $\mathrm{Cr}$ in the carbides decreased.

(3) The main reasons for carbide refinement are the distortion of the external electron layer of crystal embryos and the differences in energy between Fe ions and $\mathrm{Cr}$ ions caused by ECP. Refinement of the primary carbides caused the average content of $\mathrm{Cr}$ in the carbides to decrease, and caused the $\mathrm{Cr} / \mathrm{Fe}$ ratio from the center to the edge of the carbide particles to decrease.

(4) There were more twins and antiphase boundaries on the (001) plane of the primary carbides and more mixed dislocations in the substructure after modification of the HHCCI melt by ECP. Due to an increase in defect density, the average micro hardness of the primary carbides increased.

Author Contributions: Conceptualization, R.Z. and Y.J.; Methodology, R.Z. and B.G.; Investigation, B.G., L.L., Y.L., H.L. and D.B.; Resources, R.Z. and L.L.; Writing-Original Draft Preparation, R.Z. and B.G.; Writing-Review \& Editing, R.Z. and B.G.;

Funding: This work was supported by the National Natural Science Foundation of China (Grant No. 51261011).

Acknowledgments: The authors express their gratitude for the funding of this research by the National Science Foundation of China (51261011). The authors would like to thank Zhang Junwei and the Center of Electron Microscopy of Lanzhou University in China for their assistance in TEM analysis.

Conflicts of Interest: The authors declare no conflict of interest.

\section{References}

1. Wieczerzak, K.; Bala, P.; Dziurka, R.; Tokarski, T.; Cios, G.; Koziel, T.; Gondek, L. The effect of temperature on the evolution of eutectic carbides and $\mathrm{M} 7 \mathrm{C} 3 \rightarrow \mathrm{M} 23 \mathrm{C} 6$ carbides reaction in the rapidly solidified Fe-Cr-C alloy. J. Alloys Compd. 2017, 698, 673-684. [CrossRef]

2. Chang, C.M.; Lin, C.M.; Hsieh, C.C.; Chen, J.H.; Wu, W. Micro-structural characteristics of Fe- 40 wt $\% C r-x C$ hardfacing alloys with [1.0-4.0 wt \%] carbon content. J. Alloys Compd. 2009, 487, 83-89. [CrossRef] 
3. Powell, G.L.F.; Carlson, R.A.; Randle, V. The morphology and microtexture of M7C3 carbides in Fe-Cr-C and Fe-Cr-C-Si alloys of near eutectic composition. J. Mater. Sci. 1994, 29, 4889-4896. [CrossRef]

4. Decaudin, B.; Djega-Mariadassou, C.; Cizeron, G. Structural study of M50 steel carbides. J. Alloys Compd. 1995, 226, 208-212. [CrossRef]

5. Filipovic, M.; Romhanji, E.; Kamberovic, Z. Chemical Composition and Morphology of M7C3 Eutectic Carbide in High Chromium White Cast Iron Alloyed with Vanadium. ISIJ Int. 2012, 52, 2200-2204. [CrossRef]

6. Coronado, J.J. Effect of $(\mathrm{Fe}, \mathrm{Cr})_{7} \mathrm{C}_{3}$ carbide orientation on abrasion wear resistance and fracture toughness. Wear 2011, 270, 287-293. [CrossRef]

7. Wiengmoon, A.; Chairuangsri, T.; Brown, A.; Brydson, R.; Edmonds, D.V.; Pearce, J.T.H. Microstructural and crystallographical study of carbides in $30 \mathrm{wt}$ \% Cr cast irons. Acta Mater. 2005, 53, 4143-4154. [CrossRef]

8. Westgren, A. The Crystal Structure and Composition of the Trigonal Chromium and Manganese Carbides. Jernkontorets Ann. 1935, 118, 231-240.

9. Herbstein, F.H.; Snyman, J.A. Identification of Eckstrom-Adcock Iron Carbide as $\mathrm{Fe}_{7} \mathrm{C}_{3}$. Inorg. Chem. 1964, 3, 325-330. [CrossRef]

10. Rouault, A.; Herpin, P.; Fruchart, R. Études christallographique des carbures $\mathrm{Cr}_{7} \mathrm{C}_{3}$ et $\mathrm{Mn}_{7} \mathrm{C}_{3}$. Ann. Chim. 1970, 5, 461-470.

11. Morniroli, J.P.; Bauer-grosse, E.; Gantois, M. Crystalline defects in M7C3 carbides. Philos. Mag. A 1983, 48, 311-327. [CrossRef]

12. Morniroli, J.P.; Khachfi, M.; Courtois, A.; Gantois, M.; Mahy, J.; Dyck, D.V.; Landuyt, J.V.; Amelinckx, S. Observations of non-periodic and periodic defect structures in M7C3 carbides. Philos. Mag. A 1987, 56, 93-113. [CrossRef]

13. Carpenter, S.D.; Carpenter, D. Stacking faults and superlattice observations during transmission electron microscopy of a $(\mathrm{Fe}, \mathrm{Cr})_{7} \mathrm{C}_{3}$ carbide. Mater. Lett. 2003, 57, 4460-4465. [CrossRef]

14. Carpenter, S.D.; Carpenter, D.E.O.S.; Pearce, J.T.H. The nature of stacking faults within iron-chromium carbide of the type $(\mathrm{Fe}, \mathrm{Cr})_{7} \mathrm{C}_{3}$. J. Alloys Compd. 2010, 494, 245-251. [CrossRef]

15. Dudzinski, W.; Morniroli, J.P.; Gantois, M. Stacking faults in chromium, iron and vanadium mixed carbides of the type M7C3. J. Mater. Sci. 1980, 15, 1387-1401. [CrossRef]

16. Kagawa, A.; Okamoto, T.; Saito, K.; Ohta, M. Hot hardness of (Fe, $\mathrm{Cr})_{3} \mathrm{C}$ and $(\mathrm{Fe}, \mathrm{Cr})_{7} \mathrm{C}_{3}$ carbides. J. Mater. Sci. 1984, 19, 2546-2554. [CrossRef]

17. Zhang, Y.; Li, J.; Zhou, L.; Xiang, S. A theoretical study on the chemical bonding of 3d-transition-metal carbides. Solid State Commun. 2002, 121, 411-416. [CrossRef]

18. Xie, J.Y.; Chen, N.X.; Shen, J.; Teng, L.; Seetharaman, S. Atomistic study on the structure and thermodynamic properties of CrC, MnC, FeC. Acta Mater. 2005, 53, 2727-2732. [CrossRef]

19. Lin, C.M.; Chang, C.M.; Chen, J.H.; Wu, W. The effects of additive elements on the microstructure characteristics and mechanical properties of $\mathrm{Cr}-\mathrm{Fe}-\mathrm{C}$ hard-facing alloys. J. Alloys Compd. 2010, 498, 30-36. [CrossRef]

20. Troitskii, O.A. Pressure shaping by the application of a high energy. Mater. Sci. Eng. 1985, 75, 37-50. [CrossRef]

21. Sprecher, A.F.; Mannan, S.L.; Conrad, H. Overview No. 49: On the mechanisms for the electroplastic effect in metals. Acta Metall. 1986, 34, 1145-1162. [CrossRef]

22. Conrad, H.; Sprecher, A.F.; Cao, W.D.; Lu, X.P. Erratum to: Electroplasticity-The Effect of Electricity on the Mechanical Properties of Metals. JOM 1990, 42, 49. [CrossRef]

23. Masayuki Nakada, Y.S.; Flemings, M.C. Modification of Solidification Structures by Pulse Electric Discharging. ISIT Int. 1990, 30, 27-33. [CrossRef]

24. Li, J.; Li, S.; Li, J.; Lin, H. Modification of Solidification Structures by Pulse Electric Discharging. Scr. Metall. Mater. 1985, 31, 1691-1694. [CrossRef]

25. Conrad, H.; Guo, Z.; Sprecher, A.F. Effects of electropulse duration and frequency on grain growth in $\mathrm{Cu}$. Scr. Metall. Mater. 1990, 24, 359-362. [CrossRef]

26. Liao, X.; Zhai, Q.; Luo, J.; Chen, W.; Gong, Y. Refining mechanism of the electric current pulse on the solidification structure of pure aluminum. Acta Mater. 2007, 55, 3103-3109. [CrossRef]

27. Conrad, H. Influence of an electric or magnetic field on the liquid-solid transformation in materials and on the microstructure of the solid. Mater. Sci. Eng. A 2000, 287, 205-212. [CrossRef] 
28. Wang, J.Z.; Jin-Gang, Q.I.; Zhao, Z.F.; Guo, H.S.; Zhao, T. Effects of electric pulse modification on liquid structure of Al-5\%Cu alloy. Trans. Nonferrous Met. Soc. China (Engl. Ed.) 2013, 23, 2792-2796. [CrossRef]

29. Qi, J.; Wang, J.; He, L.; Zhao, Z.; Du, H. An investigation for structure transformation in electric pulse modified liquid aluminum. Phys. B Condens. Matter 2011, 406, 846-849. [CrossRef]

30. Zhang, Z.B.; Wang, J.Z.; Qi, J.G.; Bing, W.; He, L.J.; Cang, D.Q. The cluster size transformation model of molten alloy under pulse electric field. Sci. China 2008, 51, 302-307. [CrossRef]

31. Zhou, R.F.; Jiang, Y.H.; Zhou, R.; Zhang, L. Effect of Electric Current Pulse on Solidification Microstructure of Hypereutectic High Chromium Cast Iron Cooling from the Temperature between Liquidus and Solidus. Available online: http:/ / rinfi.fi.mdp.edu.ar/xmlui/handle/123456789/23 (accessed on 13 November 2014).

32. Cao, L.; Zhou, R.; Lu, L.I.; Jiang, Y.; Zhou, R. Effects of Pulsed Voltage on Solidified Microstructure of Low Overheat Melt of Hypereutectic High Chromium Cast Iron. Hot Work. Technol. 2017. [CrossRef]

33. Ma, S.; Xing, J.; He, Y.; Li, Y.; Huang, Z.; Liu, G.; Geng, Q. Microstructure and crystallography of M7C3 carbide in chromium cast iron. Mater. Chem. Phys. 2015, 161, 65-73. [CrossRef]

(C) 2018 by the authors. Licensee MDPI, Basel, Switzerland. This article is an open access article distributed under the terms and conditions of the Creative Commons Attribution (CC BY) license (http:/ / creativecommons.org/licenses/by/4.0/). 